УДК 616-037+618.2-082+618.77+616.36-008.6

DOI 10.11603/24116-4944.2020.1.11488

\author{
๑๐. Г. Бойчук, Е. Нсан Еком Нсед, Б. І. Дубецький \\ ДВНЗ «Івано-Франківсъкий національний медичний університет»

\section{ОСОБЛИВОСТІ ПЕРЕБІГУ ВАГІТНОСТІ У ЖІНОК ІЗ НЕПЛІДДЯМ НА ТЛІ ВНУТРІШНЬОПЕЧІНКОВОГО ХОЛЕСТАЗУ}

\begin{abstract}
Мета дослідження - з'ясувати роль порушень гепатобіліарної системи у виникненні акушерських і перинатальних ускладнень у жінок з вагітністю після застосування допоміжних репродуктивних технологій (ДРТ).

Матеріали та методи. Проаналізовано 260 амбулаторних карт жінок, які звернулись із приводу лікування безпліддя і яким було призначено та проведено застосування програми ДРТ (запліднення in vitro). Із 260 розпочатих циклів вагітність настала у 56 (21,8 \%) жінок (основна група). 30 жінок, вагітність у яких настала без застосування ДРТ, склали контрольну групу.

Результати дослідження та їх обговорення. Захворювання печінки та жовчовивідних шляхів займають важливе місце серед екстрагенітальної патології у вагітних і досить часто сприяють розвитку акушерської патології. Вагітність, що настала після використання допоміжних репродуктивних технологій на фроні масивної гормональної підтримки, може призвести до тяжких необоротних змін гепатобіліарної системи. Проведений ретроспективний аналіз встановив, що вагітність після ДРТ у жінок із внутрішньопечінковим холестазом має свої особливості: суттєво вища частота викиднів та завмерлих вагітностей, загрози передчасних пологів, ранніх гестозів, прееклампсії тяжкого ступеня та затримки росту плода. Майже 40 \% дітей народились у стані ассріксії, причому в 11,1% відмічено тяжкий їі ступінь, третина цих дітей була недоношеною, і 40,0 \% мали ознаки гіпотрофрії, а у 66,7 \% дітей був порушений перебіг ранньої неонатальної адаптації. Вищою була і перинатальна смертність.

Висновки. Вагітність після ДРТ у жінок з внутрішньопечінковим холестазом має свої особливості: суттєво вища частота викиднів та завмерлих вагітностей, загрози передчасних пологів, ранніх гестозів, прееклампсії тяжкого ступеня та затримки росту плода, що потребують детальнішого дослідження для розробки патогенетично обґрунтованої системи лікувальнопрофрілактичних заходів.
\end{abstract}

Ключові слова: вагітність; непліддя; внутрішньопечінковий холестаз.

ОСОБЕННОСТИ ТЕЧЕНИЯ БЕРЕМЕННОСТИ У ЖЕНЩИН С БЕСПЛОДИЕМ НА ФОНЕ ВНУТРИПЕЧЕНОЧНОГО ХОЛЕСТАЗА

Цель исследования - выяснить роль нарушений гепатобилиарной системы в возникновении акушерских и перинатальных осложнений у женщин с беременностью после применения вспомогательных репродуктивных технологий (ВРТ).

Материалы и методы. Проанализированы 260 амбулаторных карт женщин, которые обратились по поводу лечения бесплодия и которым было назначено и проведено применение программы ВРТ (оплодотворение in vitro). C 260 начатых циклов беременность наступила у 56 (21,8 \%) женщин (основная группа). 30 женщин, беременность у которых наступила без применения ВРТ, составили контрольную группу.

Результаты исследования и их обсуждение. Заболевания печени и желчевыводящих путей занимают важное место среди экстрагенитальной патологии у беременных и довольно часто способствуют развитию акушерской патологии. Беременность, наступившая после использования вспомогательных репродуктивных технологий на фоне массивной гормональной поддержки, может привести к тяжелым необратимым изменениям пищеварительной системы. Проведенный ретроспективный анализ установил, что беременность после ВРТ у женщин с внутрипеченочным холестазом имеет свои особенности: существенно выше частота выкидышей и замерших беременностей, угрозы преждевременных родов, ранних гестозов, преэклампсии тяжелой степени и задержки роста плода. Почти $40 \%$ детей родились в состоянии ассриксии, причем в 11,1 \% отмечено тяжелую ее степень, треть этих детей была недоношенной, 40,0 \% имели признаки гипотрофии, а у 66,7 \% детей было нарушенным течение ранней неонатальной адаптации. Выше была и перинатальная смертность.

Выводы. Беременность после ВРТ у женщин с внутрипеченочным холестазом имеет свои особенности: существенно выше частота выкидышей и замерших беременностей, угроза преждевременных родов, ранних гестозов, преэклампсии тяжелой степени и задержки роста плода, что требует детального исследования для разработки патогенетически обусловленной системы лечебно-просилактических мероприятий.

Ключевые слова: беременность; бесплодие; внутрипеченочный холестаз.

MANAGEMENT OF PREGNANCY IN WOMEN WITH INFERTILITY IN CASE OF CONCOMITANT INTRAHEPATIC CHOLESTASIS

The aim of the study - to examine the features of pregnancy and the condition of newborns in women with infertility after the use of assisted reproductive technologies.

Materials and Methods. We analyzed 260 outpatient records of women treated for infertility with the use of an ART program (in vitro fertilization). 56 out 260 women $(21.8 \%$ ) got pregnant (basic group). The reference group consisted of 30 women who got pregnant without the use of ART.

Results and Discussion. Diseases of liver and biliary ducts are important extragenital pathologies in pregnant women and quite often contribute to the development of obstetric pathologies. In their turn, pregnancies achieved with the use 
of assisted reproductive technologies, under a massive hormonal support, may lead to severe irreversible changes in the hepatobiliary system. Our retrospective analysis established that pregnancy after the use of ART in women with intrahepatic cholestasis has the following peculiarities: a significantly higher frequency of miscarriages and missed miscarriages, threats of preterm labor, early gestosis, severe preeclampsia and intrauterine growth restriction. Almost $40 \%$ of the newborns presented asphyxia at birth, $11.1 \%$ a severe one, a third of the babies were born prematurely and $40 \%$ presented signs of hypotrophy, while $66.7 \%$ had a disturbed course of early neonatal adaptation. The percentage of perinatal mortality was also higher.

Conclusions. The issues of etiology, pathogenesis, the risk factors determining the development of intrahepatic cholestasis, the principles of treatment and prevention still remain the subject of discussion and their specific mechanisms require a more detailed research to develop a pathogenetically substantiated system of treatment and prevention measures.

Key words: pregnancy; infertility; intrahepatic cholestasis.

ВстУп. У всьому світі відмічається посилений інтерес до розвитку допоміжних репродуктивних технологій (ДРТ), що пов'язано із зростаючою проблемою непліддя (Кулаков В. І., 2005). На сьогодні більше 1 млн дітей у світі народилося завдяки ДРТ. Актуальним на сьогодні $€$ перебіг вагітності, що настала внаслідок застосування допоміжних репродуктивних технологій (Жилка Н. Я. і співавт., 2001; Венцківський Б. М., 2004; Тютюнник В. Л., 2004; Сенчук А. Я. і співавт., 2005). Частота настання вагітності після ДРТ, за даними всесвітнього реєстру, складає 20-30 \%, частота виникнення гестаційних ускладнень при цьому коливається в межах 18-44 \% (Беглице Д. А., 2003). За даними різних авторів, вагітність, що настала в результаті застосування допоміжних репродуктивних технологій, належить до категорії високого ризику щодо акушерських ускладнень [1-5].

Екстрагенітальна патологія $є$ однією з головних причин материнських і перинатальних втрат на сучасному етапі (Степанківська Г. К. та співавт., 1998; Дашкевич В. Є. та співавт., 2000; Коломійцева А. Г. та співавт., 2001). Внутрішньопечінковий холестаз у вагітних (BПХ) є другою за частотою після вірусного гепатиту причиною жовтяниці у вагітних і складає до 20-25 \% випадків (Лобзин Ю. В. і співавт., 2003; Mil-riewicz P., 2003; Ropponen A.; 2006). Внутрішньопечінковий холестаз вагітних має практичний інтерес, оскільки дана нозологія є пограничною між акушерською, інфекційною і гепатологічною патологією [6-8]. Питання етіології, патогенезу, фрактори ризику, що є пусковим моментом у розвитку ВПХ, принципи терапії і профрілактики до цього часу є предметом дискусії (Кан В. К., 2000; Кузьмина В. Н., 2001; Линева О. И., 2000; Glantz A., 2004; Lammert F., 2000). Навіть при нормальному перебігу вагітності відбуваються зміни фрункції гепатобіліарної системи, які до кінця вагітності призводять до виснаження резервних можливостей [9-11]. Також при вагітності, що настала внаслідок допоміжних репродуктивних технологій, має місце збільшення впливу прогестерону на тонус та моторику жовчовивідних шляхів, внаслідок чого виникають холелітіаз та холестаз у здорових вагітних [12-15]. Частота перинатальних втрат при ВПХ може досягати від 4,7 до $35 \%$. При рецидивному холестазі ризик антенатальної загибелі плода в 4 рази вищий, ніж при фрізіологічному перебігу вагітності (Li M. K., 2004; Mil S., 2005; Savonius H., 2000; Ropponen A., 2006). Відсутність єдиних підходів до питань прогнозування, діагностики і медикаментозної корекції [16] внутрішньопечінкового холестазу у вагітних після застосування допоміжних репродуктивних технологій характеризує дану проблему як актуальну та значиму для сучасного акушерства [17-21].
Актуальність даної проблеми зумовлена широким розповсюдженням патології гепатобіліарної системи у жінок; великою частотою розвитку хронічних фрорм; наявністю захворювань із мінімальними і стертими клінічними проявами; труднощами специфічної діагностики; збільшенням антропогенних навантажень.

METА ДОСЛІДЖЕННЯ - З'ясувати роль порушень гепатобіліарної системи у виникненні акушерських і перинатальних ускладнень у жінок з вагітністю після застосування ДРТ.

МАТЕРІАЛИ ТА МЕТОДИ. Проаналізовано 260 амбулаторних карт жінок, які звернулись $з$ приводу лікування безпліддя і яким було призначено та проведено застосування програми ДРТ (запліднення in vitro). I3 260 розпочатих циклів вагітність настала у 56 (21,8 \%) жінок (основна група). 30 вагітних жінок без непліддя в анамнезі склали контрольну групу.

Для з'ясування ролі патології гепатобіліарної системи у розвитку порушень перебігу вагітності ми поділили 56 жінок, у яких вагітність настала після застосування ДРТ (основна група), на 2 підгрупи: 1-ша - 14 вагітних із діагностованим внутрішньопечінковим холестазом, 2-га - 42 вагітних після ДРТ без ознак функціональних порушень гепатобіліарної системи. До фрункціональних порушень ми відносили наявність УЗД-ознак порушень печінки та біохімічних маркерів (трансамінази, лужна фоосратаза, білірубін). 30 вагітних жінок без непліддя в анамнезі склали контрольну групу.

РЕЗУЛЬТАТИ ДОСЛІДЖЕННЯ ТА ЇХ ОБГОВОРЕННЯ. Як видно з даних таблиці 1, у вагітних жінок із непліддям в анамнезі (після застосування ДРТ) перебіг I половини вагітності достовірно частіше був ускладнений порівняно $з$ таким у вагітних контрольної групи (без непліддя в анамнезі). Найчастіше відмічено загрозу переривання вагітності (39,2 та 21,8 \% у жінок 1-ї та 2-ї групи проти $10,0 \%$ у жінок контрольної групи, p<0,05). Причому частота ускладнення не відрізняється у жінок основних груп, оскільки втрата вагітності $€$ загальновизнаною проблемою ДРТ. У вагітних із внутрішньопечінковим холестазом суттєво вища частота викиднів та завмерлих вагітностей, що також характерно при застосуванні репродуктивних технологій. Частота ранніх гестозів у жінок 1-ї групи суттєво вища не тільки відносно жінок контрольної групи, а й порівняно з вагітними 2-ї групи (31,3 проти 11,2 \%, $p<0,05)$, що може бути пов'язано саме $з$ наявністю розладів печінки.

Перебіг II половини вагітності у жінок основних груп також був ускладненим (табл. 2). 
Таблиця 1. Ускладнення перебігу I половини вагітності в обстежених жінок, абс. ч. (\%)

\begin{tabular}{|l|c|c|c||}
\hline \multirow{2}{*}{\multicolumn{1}{|c|}{ Показник }} & \multicolumn{2}{|c|}{ Вагітні після ДРТ } & \multirow{2}{*}{$\begin{array}{c}\text { Контрольна група, } \\
\mathrm{n}=30\end{array}$} \\
\cline { 2 - 3 } & $\begin{array}{c}\text { 1-ша, } \\
\mathrm{n}=14\end{array}$ & $\begin{array}{c}2-\text {-га, } \\
\mathrm{n}=42\end{array}$ & $2(8,0)$ \\
\hline Ранній гестоз & $5(31,3)^{\star \wedge}$ & $4(11,2)$ & $1(2,0)$ \\
\hline Викидень, завмерла вагітність & $3(16,7)^{\star}$ & $2(6,2)$ & $3(10,0)$ \\
\hline Загроза переривання вагітності & $6(39,2)^{\star}$ & $9(21,8)^{\star}$ & $4(14,0)$ \\
\hline Анемія & $4(22,2)$ & $7(17,1)$ & \\
\hline
\end{tabular}

Примітка. * - різниця достовірна щодо показника вагітних без непліддя в анамнезі (p<0,05); ^ - різниця достовірна щодо показника вагітних після ДРТ без гепатобіліарної патології ( $p<0,05)$.

Таблиця 2. Ускладнення перебігу II половини вагітності в обстежених жінок, абс. ч. (\%)

\begin{tabular}{|l|c|c|c||}
\hline \multirow{2}{*}{\multicolumn{1}{|c|}{ Показник }} & \multicolumn{2}{c||}{ Вагітні після ДРТ } & \multirow{2}{*}{$\begin{array}{c}\text { Контрольна група, } \\
\mathrm{n}=30\end{array}$} \\
\cline { 2 - 4 } & $\begin{array}{c}1 \text {-ша, } \\
\mathrm{n}=14\end{array}$ & $\begin{array}{c}2 \text {-га, } \\
\mathrm{n}=42\end{array}$ & $3(6,0)$ \\
\hline Загроза передчасних пологів & $5(37,1)^{\star \wedge}$ & $35(17,1)^{\star}$ & - \\
\hline Завмерла вагітність & $1(10,2)^{\star}$ & $5(2,8)$ & $4(8,0)$ \\
\hline Плацентарна недостатність & $5(39,1)^{\star}$ & $45(24,9)^{\star}$ & $9(18,0)$ \\
\hline Анемія & $3(31,2)^{\star}$ & $29(21,6)$ & $2(4,0)$ \\
\hline Дистрес плода & $3(31,2)^{\star}$ & $34(24,1)^{\star}$ & $2(4,0)$ \\
\hline Прееклампсія & $4(33,5)^{\star \wedge}$ & $21(18,1)^{\star}$ & $2(4,0)$ \\
\hline - легкого ступеня & $2(11,1)$ & $18(14,0)^{\star}$ & - \\
\hline - тяжкого ступеня & $3(31,2)^{\star \wedge}$ & $3(2,3)$ & $1(2,0)$ \\
\hline ЗРП & $5(39,1)^{\star \wedge}$ & $22(18,2)^{\star}$ & \\
\hline
\end{tabular}

Примітка. * - різниця достовірна щодо показника вагітних без непліддя в анамнезі ( $<<0,05)$; ^ - різниця достовірна щодо показника вагітних після ДРТ без гепатобіліарної патології $(\mathrm{p}<0,05)$.

У вагітних після ДРТ обох груп закономірно висока частота завмерлих вагітностей та загрози передчасних пологів.

Майже у половини жінок 1-ї групи та третини 2-ї групи спостерігали плацентарну недостатність і, відповідно, високу частоту затримки росту плода, яка у жінок 1-ї групи перевищувала у 2 рази показник жінок 2-ї групи (33,3 проти 17,1 \%, p<0,05).

У третини жінок 1-ї групи та чверті 2-ї групи діагностовано дистрес плода (31,3 та 24,4 \% відповідно проти $4,0 \%$ у жінок без непліддя в анамнезі, p<0,05). Частота анемії ускладнила II половину вагітності у 31,2 \% жінок 3 функціональними розладами печінки проти 21,6 \% жінок контрольної групи (p<0,05). Звертає на себе увагу висока частота прееклампсії - одного з найнебезпечніших ускладнень вагітності. Причому в 33,5 \% жінок із розладами гепатобіліарної системи відмічено прееклампсію тяжкого ступеня, що майже у 10 разів перевищувало частоту таких випадків у жінок 2-ї групи, тобто з високою ймовірністю зумовлено саме незадовільним станом печінки.

Слід зауважити, що оптимальний термін розродження пацієнток із порушеннями функції гепатобіліарної системи на сьогодні не визначено. Зустрічаються рекомендації стосовно родозбудження в терміні 38 тижнів із попередньою оцінкою зрілості легенів плода. Але при тяжкому холестазі, що перебігає з яскраво вираженими клінічними ознаками, розродження може бути проведено вже в 36 тижнів. Метод розродження вирішується індивідуально, тобто протипоказань щодо пологів через пиродні пологові шляхи при даній патології немає.
Але аналіз частоти ускладнень при пологах у жінок обстежених груп (табл. 3) показав закономірно високий відсоток застосування операції кесаревого розтину в жінок після ДРТ (66,7 та 58,1 \% відповідно у жінок 1-ї та 2-ї груп проти 7,0 \% у жінок контрольної групи, р<0,05).

Достовірно вища у жінок після ДРТ також частота передчасних пологів та дистресу плода (38,9 та 31,0 \% у жінок 1-ї та 2-ї групи проти 10,0 \% у жінок контрольної групи, р<0,05). Слід відмітити високу частоту крововтрат при пологах у жінок 1-ї групи (27,8 \% проти 10,9 та 4,0 \% у жінок 2-ї та контрольної груп, р<0,05).

Недоношеною була третина дітей 1-ї групи (табл. 4), що достовірно перевищувало частку недоношених не тільки в контрольній групі, а й серед дітей від жінок після ДРТ без ознак гепатобіліарної патології $(p<0,05)$. ще більша частина дітей мала ознаки гіпотрофрії, що зумовлено як недоношеністю, так і затримкою розвитку плода, як наслідок, дітей від матерів основних груп пізно прикладали до грудей. Більш ніж у $60 \%$ дітей 1-ї групи мали місце порушення періоду неонатальної адаптації (66,7 \% проти 36,5 та 6,1 \%, відповідно, дітей від матерів 2-ї та контрольної групи, $\mathrm{p}<0,05)$.

У ранньому неонатальному періоді померла 1 дитина 3 1-ї та 3 - 3 2-ї групи, тобто неонатальна смертність склала 66,7 \% та 11,5 \%. Загальна перинатальна смертність (з урахуванням антенатальної загибелі плода) склала, відповідно, 166,7 \%о та 58,8 \%о. 
Таблиця 3. Частота ускладнень при пологах в обстежених жінок, абс. ч. (\%)

\begin{tabular}{|c|c|c|c|}
\hline \multirow[b]{2}{*}{ Показник } & \multicolumn{2}{|c|}{ Вагітні після ДРТ } & \multirow{2}{*}{$\begin{array}{c}\text { Контрольна група, } \\
\text { n=30 }\end{array}$} \\
\hline & $\begin{array}{l}\text { 1-ша, } \\
\mathrm{n}=14\end{array}$ & $\begin{array}{l}2-r a \\
n=42\end{array}$ & \\
\hline Кесарів розтин & $8(56,3)^{\star}$ & $20(48,1)^{\star}$ & $14(7,0)$ \\
\hline Передчасні пологи & $3(21,2)^{\star}$ & $5(11,7)^{\star}$ & $1(2,0)$ \\
\hline Передчасний вилив навколоплодових вод & $3(21,2)$ & $7(17,1)$ & $6(12,0)$ \\
\hline $\begin{array}{l}\text { Тривалість безводного проміжку більше } \\
8 \text { год }\end{array}$ & $2(16,7)$ & $6(14,7)^{\star}$ & $3(6,0)$ \\
\hline Слабкість пологової діяльності & $2(16,7)$ & $9(21,7)$ & $9(18,0)$ \\
\hline Швидкі (стрімкі) пологи & $1(5,6)$ & $1(2,3)$ & $2(4,0)$ \\
\hline Епізіотомія & $4(27,8)$ & $11(27,1)$ & $10(20,0)$ \\
\hline Дистрес плода в пологах & $5(28,9)^{\star}$ & $5(11,7)^{\star}$ & $5(10,0)$ \\
\hline Кровотеча >0,5 \% маси тіла & $5(28,9)^{\star \wedge}$ & $4(10,9)$ & $2(4,0)$ \\
\hline Оповиття пуповиною & $6(33,3) * \wedge$ & $6(14,7)$ & $5(10,0)$ \\
\hline
\end{tabular}

Примітка. * - різниця достовірна щодо показника вагітних без непліддя в анамнезі (p<0,05); ^ - різниця достовірна щодо показника вагітних після ДРТ без гепатобіліарної патології $(p<0,05)$.

Таблиця 4. Показники стану новонароджених, абс. ч. (\%)

\begin{tabular}{|l|c|c|c||}
\hline \multirow{2}{*}{\multicolumn{1}{|c|}{ Показник }} & Діти від матерів після ДРТ & \multirow{2}{*}{$\begin{array}{c}\text { Контрольна група, } \\
\mathrm{n}=30\end{array}$} \\
\cline { 2 - 4 } & $\begin{array}{c}\text { 1-ша, } \\
\mathrm{n}=14\end{array}$ & $\begin{array}{c}2-\text { га, } \\
\mathrm{n}=42\end{array}$ & $1(2,0)$ \\
\hline Недоношеність & $5(28,9)^{\star \wedge}$ & $7(14,3)^{\star}$ & $3(6,1)$ \\
\hline Гіпотрофія & $6(33,3)^{\star \wedge}$ & $9(21,5)^{\star}$ & $1(2,0)$ \\
\hline Втрата маси тіла більше 10\% & $7(46,7)^{\star}$ & $13(31,7)^{\star}$ & $2(4,1)$ \\
\hline Пізнє прикладання до грудей & $7(46,7)^{\star \wedge}$ & $10(24,8)^{\star}$ & $3(6,1)$ \\
\hline Порушення періоду адаптації & $9(66,7)^{\star \wedge}$ & $14(33,5)^{\star}$ & \\
\hline
\end{tabular}

Примітка. * - різниця достовірна щодо показника дітей контрольної групи (р<0,05); ^ - різниця достовірна щодо показника дітей жінок без гепатобіліарної патології, вагітність у яких настала після ДРТ $(p<0,05)$.

ВисновкИ. 1. Проведений ретроспективний аналіз встановив, що перебіг вагітності після застосування програм ДРТ достовірно частіше був ускладненим порівняно з таким у жінок без непліддя в анамнезі.

2. Вагітність після ДРТ у жінок з внутрішньопечінковим холестазом має свої особливості: суттєво вища частота викиднів та завмерлих вагітностей, загрози передчасних пологів, ранніх гестозів, прееклампсії тяжкого ступеня та затримки росту плода.

3. Таким чином, наявність внутрішньопечінкового холестазу у жінок з непліддям відіграє певну роль у виношуванні вагітності після ДРТ, виникненні її ускладнень, негативних наслідків для жінки та новонародженої дитини,

\section{СПИСОК ЛІТЕРАТУРИ}

1. Рудакова Е. Б. Вспомогательные репродуктивные технологии. Проблемы потерь беременности / Е. Б. Рудакова, И. В. Бесман // Лечащий врач. - 2010. - № 3. - С. 46-48.

2. Дубоссарская Ю. А. Патология гепатобилиарной системы в практике гинеколога / Ю. А. Дубоссарская // Медицинские аспекты здоровья женщины. - 2010. - № 3 (30). - C. 12-19.

3. Стероидные гормоны, миома матки и нарушения функции печени: патогенез и перспективы лечения / 3. Р. Кантемирова, А. М. Торчинов, Т. А. Жигулина [и др.] // Лечащий врач. - 2003. - № 10. - С. 18-20. конкретні механізми чого потребують більш детального дослідження для розробки патогенетично обґрунтованої системи лікувально-профрілактичних заходів.

ПЕРСПЕКТИВИ ПОДАЛЬШИХ ДОСЛІДЖЕНЬ. Функціональне навантаження на гепатобіліарну систему печінки під час програми ДРТ, внаслідок терапії супроводу та подальшої вагітності може призвести до необоротних змін та порушення соматичного здоров'я жінки, що потребує подальших досліджень. Патогенетично обґрунтоване лікування створить умови для попередження акушерських та перинатальних ускладнень у вагітних із непліддям після використання ДРТ та з проявами раннього гестозу на тлі внутрішньопечінкового холестазу. 
7. Bacq Y. Liver diseases unique to pregnancy: a 2010 update / Y. Bacq // Clin Res Hepatol Gastroenterol. - 2011. No. 35. - P. 182-193.

8. Особливості етіології та патогенезу внутрішньопечінкового холестазу вагітних / О. І. Федів, С. В. Вірста, Н. С. Спащук, Т. В. Заболотна // Клінічна та експериментальна патологія. - 2013. - Т. 12, №. 1. - С. 197-200.

9. Гормональний гомеостаз жінок з безпліддям та фрункціональними порушеннями гепатобіліарної системи / В. В. Камінський, В. В. Суменко, Т. В. Коломійченко, О. Г. Бойчук// Репродуктивна ендокринологія. - 2016. - № 5 (31). - С. 8-14.

10. Boychuk A. G. Role of hemostasis violations in ART programs efficiency in women with hepatobiliary system pathology/ A. G. Boychuk, A. I. Zhdanovich, T. V. Kolomiychenko // European Journal of Biomedical and Life Sciences. - 2016. No. 2. - P. 36-39.

11. Морфологічні та імуногістохімічні особливості плацент жінок після ДРТ з функціональними порушеннями печінки / В. В. Камінський, О. Г. Бойчук, Т. В. Коломійченко [та ін.] // Репродуктивна ендокринологія. - 2016. - № 3 (29). - С. 24-27.

12. Boychuk A. G. Management system for women with infertility and nonalcoholic fatty liver disease / A. G. Boychuk // Austrian Journal of Technical and Natural Sciences. - 2016. No. 5-6. - P. 13-16.

13. БойчукА. Г. Новые подходы кснижениюперинатальных потерь у женщин с нарушениями печени при индуцированной беременности / А. Г. Бойчук // Репродуктивное здоровье. Восточная Европа. - 2016. - № 4 (46). - С. 479-484.

14. The role of vascular deregulation in induction of perinatal disorders among the women with high-risk inducted pregnancy : The 24th EBCOG European Congress of Obstetrics and Gynaecology. Torino, Italy, 19-21 May 2016 / V. Kaminskiy,
A. Kaminskiy, T. Kolomiichenko, O. Boychuk // European Journal of Obstetrics \& Gynecology and Reproductive Biology. - 2016. - Vol. 206 . - P. e53.

15. Drossman D. A. The functional gastrointestinal disorders and the Rome III process / D. A. Drossman // Gastroenterology. - 2006. - Vol. 130. - P. 1377-1390.

16. Vainshtein S.G. Food fiber - research results and outlook / S. G. Vainshtein, A. M. Masik, I. V. Zhulkevich // Voprosy pitaniia. - 1988. - Vol. 6. - P. 8-12.

17. Nsan Ekom Nsed E. Особливості гормонального гомеостазу жінок із безпліддям та внутрішньопечінковим холестазом / Е. Нсан Еком Нсед, О. Г. Бойчук // Здобутки клінічної і експериментальної медицини. - 2020. - № 1. - С. 83-88.

18. Two cases of first onset intrahepatic cholestasis of pregnancy associated with moderate ovarian hyperstimulation syndrome after IVF treatment and review of the literature / M. F. Mutlu, K. Aslan, I. Guler [et al.] // Journal of Obstetrics and Gynaecology. - 2017. - Vol. 37. - Issue 5. - P. 547-549.

19. Intrahepatic cholestasis of pregnancy: are in vitro fertilization pregnancies at risk? / S. Alemdaroğlu, Ş. Y. Baran, G. D. Durdağ [et al.] // The Journal of Maternal-Fetal \& Neonatal Medicine. - 2020. - Access mode : https://doi.org/10.1080/147 67058.2020.1765331.

20. Impacts of different methods of conception on the perinatal outcome of intrahepatic cholestasis of pregnancy in twin pregnancies / C. Feng, W.-J. Li, R.-H. He [et al.] // Sci. Rep. - 2018. - Vol. 8. - P. 3985. - Access mode : https://doi. org/10.1038/s41598-018-22387-6.

21. The impact of assisted reproductive technology and chorionicity in twin pregnancies complicated by obstetric cholestasis / G. Pacella, G. Salsi, T. Arcangeli [et al.] // The Journal of Maternal-Fetal \& Neonatal Medicine. - 2016. Vol. 29, Issue 9. - P. 1481-1484.

6. Ignatova, T.M. (2009). Zabolevaniya pecheni u beremennykh [Liver diseases in pregnant women]. Meditsinskiy vestnik Severnogo Kavkaza - Medical Bulletin of the North Caucasus, 2, 88-93 [in Russian].

7. Bacq, Y. (2011). Liver diseases unique to pregnancy: a 2010 update. Clin. Res. Hepatol. Gastroenterol., 35, 182-193.

8. Fediv, O.I., Virsta, S.V., Spashchuk, N.S., \& Zabolotna, T.V. (2013). Osoblyvosti etiolohii ta patohenezu vnutrishnopechinkovoho kholestazu vahitnykh [Peculiarities of etiology and pathogenesis of intrahepatic cholestasis of pregnant women]. Klinichna ta eksperymentalna patolohiia - Clinical and Experimental Pathology, 12, 1, 197-200 [in Ukrainian].

9. Kaminskyi, V.V., Sumenko, V.V., Kolomiichenko, T.V., \& Boichuk, O.H. (2016). Hormonalnyi homeostaz zhinok z bezpliddiam ta funktsionalnymy porushenniamy hepatobiliarnoi systemy [Hormonal homeostasis of women with infertility and functional disorders of the hepatobiliary system]. Reproduktyvna endokrynolohiia - Reproductive Endocrinology, 5 (31), 8-14 [in Ukrainian].

10. Boychuk, A.G., Zhdanovich, A.I., \& Kolomiychenko, T.V. (2016). Role of hemostasis violations in ART programs efficiency in women with hepatobiliary system pathology. European Journal of Biomedical and Life Sciences, 2, 36-39.

11. Kaminskyi, V.V., Boichuk, O.H., Kolomiichenko, T.V., Yeshchenko, O.I. \& Kylykhevych, S.M. (2016). Morfolohichni ta imunohistokhimichni osoblyvosti platsent zhinok pislia DRT z funktsionalnymy porushennyamy pechinky [Morphological and immunohistochemical features of placentas in women after ART with functional liver disorders]. Reproduktyvna endokrynolohiia - Reproductive Endocrinology, 3 (29), 24-27 [in Ukrainian]. 
12. Boychuk, A.G. (2016). Management system for women with infertility and nonalcoholic fatty liver disease. Austrian Journal of Technical and Natural Sciences, 5-6, 13-16.

13. Boychuk, A.G. (2016). Novyye podkhody k snizheniyu perinatalnykh poter $u$ zhenshchin $\mathrm{s}$ narusheniyami pecheni pri indutsirovannoy beremennosti [New approaches to reducing perinatal losses in women with liver disorders during induced pregnancy]. Reproduktivnoye zdorovye. Vostochnaya Yevropa - Reproductive health. Eastern Europe, 4 (46), 479-484 [in Russian].

14. Kaminskiy, V., Kaminskiy, A., Kolomiichenko, T., \& Boychuk, O. (2016). The role of vascular deregulation in induction of perinatal disorders among the women with high-risk inducted pregnancy: The 24th EBCOG European Congress of Obstetrics and Gynaecology. Torino, Italy. European Journal of Obstetrics \& Gynecology and Reproductive Biology, 206, e53.

15. Drossman, D.A. (2006). The functional gastrointestinal disorders and the Rome III process. Gastroenterology, 130, 1377-1390.

16. Vainshtein, S.G., Masik, A.M., \& Zhulkevich, I.V. (1988). Food fiber-research results and outlook. Voprosy pitaniia, 6 , 8-12.

17. Nsan Ekom Nsed, E., \& Boichuk, O.H. (2020). Osoblyvosti hormonalnoho homeostazu zhinok iz bezpliddiam ta vnutrishnopechinkovym kholestazom [The peculiarities of hormonal homeostasis in women with infertility and intrahepatic cholestasis]. Zdobutky klinichnoi i eksperymentalnoi medytsyny -Achievements of Clinical and Experimental Medicine, 1, 83-88 [in Ukrainian].

18. Mutlu, M.F., Aslan, K., Guler, I., Mutlu, I., Erdem, M., Bozkurt, N., \& Erdem, A. (2017). Two cases of first onset intrahepatic cholestasis of pregnancy associated with moderate ovarian hyperstimulation syndrome after IVF treatment and review of the literature. Journal of Obstetrics and Gynaecology, 37, 5, 547-549.

19. Alemdaroğlu, S., Baran, Ş.Y., Durdağ, G.D., Şimşek, S.Y., Yetkinel, S., Didem A.Y., ..., \& Şimşek, E. (2020). Intrahepatic cholestasis of pregnancy: are in vitro fertilization pregnancies at risk? The Journal of Maternal-Fetal \& Neonatal Medicine. DOI: https://doi.org/10.1080/14767058.2020.1765331.

20. Feng, C., Li, W.-J., He, R.-H., Sun, X.-W., Wang, G.. \& Wang, L.-Q. (2018). Impacts of different methods of conception on the perinatal outcome of intrahepatic cholestasis of pregnancy in twin pregnancies. Sci. Rep., 8, 3985. DOI: https://doi. org/10.1038/s41598-018-22387-6.

21. Pacella, G., Salsi, G., Arcangeli, T., Youssef, A., Farina, A., Bacchi-Reggiani, M.L., ..., \& Ghi, T. (2016). The impact of assisted reproductive technology and chorionicity in twin pregnancies complicated by obstetric cholestasis. The Journal of Maternal-Fetal \& Neonatal Medicine, 29, 9, 1481-1484.

Отримано 12.05.20

Прийнято до друку 16.06.20

Електронна адреса для листування: I.bojchuk@gmail.com 